\title{
Locative orientation and locative arguments: A case study from Kinyarwanda
}

\author{
Kyle Jerro*
}

\begin{abstract}
Previous work has investigated various syntactic and semantic properties of locative PPs, but a lesser-studied set of facts is so-called 'locative orientation' - the variable locating of participants in the location described by the locative. In Kinyarwanda (Bantu; Rwanda), the presence/absence of the applicative morpheme -ir corresponds to an alternation in orientation: with the non-applied variant, the locative only necessarily describes the object's location; with the applied variant, all participants must be at the location described by the locative. I argue that Kinyarwanda locatives are neither prepositions (but rather noun class prefixes) nor adjuncts, and therefore cannot be analyzed as intersectional (adjunct) modifiers. On the view that locatives are (internal) arguments, I instead propose that locative applicatives in Kinyarwanda mark a paradigmatic relationship between applied and non-applied variants in which there is an increase in the number of entailments associated with an internal argument.
\end{abstract}

Keywords. locatives; syntax-semantics interface; verb meaning; Kinyarwanda 1. Introduction. Previous work has investigated various syntactic and semantic properties of locative phrases, including the vector-spatial analyses of locations (Zwarts \& Winters 1997, 2000, Zwarts 2005), how locative descriptions interface with conceptual structure (Jackendoff 1983), and how differences in the attachment of locative phrases changes the interpretation of the locative (Maienborn 2001). A lesser-studied set of facts is so-called 'locative orientation'-the variable locating of participants at the location described by the locative phrase. In English, the location of participants is determined by both verb and preposition. For example, while in (1a) the prepositional phrase 'across the street' describes the location of the object in relation to the subject, in (1b), the prepositional phrase 'at the meeting' only necessarily describes the location of the subject.

(1) a. Lana watched the spy across the street

b. Pam criticized Cheryl at the meeting

These types of orientation shift have been captured in previous work by a combination of verb meaning, prepositional meaning, and general principles about the relationships between participants, locatives, and the events they are linked to (Keenan \& Faltz 1985, Nam 1995, Kracht 2002).

In Kinyarwanda (Bantu JD.67; Rwanda), the presence/absence of the applicative morpheme -ir (Kimenyi 1980:36-37) marks an alternation in locative orientation. In the non-applied variant, the locative only necessarily describes the location of the verbal object. In the applied variant (allomorph -iy), both the subject and object must be at the location described by the locative. Consider the example in (2) where the non-applied variant in (a) only necessarily describes the

\footnotetext{
*I am grateful to Gilbert Habarurema, Félicité Ingabire, Trésor Cyubahiro, and Olive Nyiracumi for the judgments and discussion of these data. Thanks to John Beavers, Hannah Gibson, Nancy Kula, Lutz Marten, Neil Myler, and the audience of the LSA meeting in New Orleans for their helpful insights into various aspects of the analysis presented here. This work was supported in part by the National Science Foundation under grant no. BCS-1451566 awarded to John Beavers and Kyle Jerro. Any errors are entirely mine. Author: Kyle Jerro, University of Essex (k.jerro@essex.ac.uk).
} 
location of the house, while the applied variant in (b) necessarily describes the location of both the house and the chief. ${ }^{1}$
a. Umu-yobozi y- $\emptyset$-ubats-e in-zu mu mu-jyi.
1-chief 1S-PST-build-PRFV 9-house 18 3-town
'The chief built the house in town.'
Speaker Judgment: Only the house must be in town
b. Umu-yobozi y- $\emptyset$-ubak-iy-e in-zu mu mu-jyi.
1-chief 1S-PST-build-APPL-PRFV 9-house 18 3-town
'The chief built the house in town'.
Speaker Judgment: The chief and the house must be in town

This crucially differs from the English pattern in (1) in that locative orientation is tied up with the alternation between applied/non-applied verb meanings, and thus cannot be linked to the meaning of the locative $m u$ in a parallel way to the meanings of English prepositions.

More generally, Bantu languages vary in whether locative phrases are arguments or adjuncts (Welmers 1973, Bresnan \& Kanerva 1989, Bresnan 1994, Bresnan \& Mchombo 1995, Rugemalira 2004, Riedel \& Marten 2012, Guérois 2016, Zeller \& Ngoboka 2018). Specifically, locative phrases have been shown to be DP arguments in some languages-such as Chichewa (Mchombo 2004) — and PP adjuncts in others_-such as Siswati (Marten 2010). Previous work on Kinyarwanda has shown that locatives in this language are arguments (Ngoboka 2016, Jerro 2016b, Zeller \& Ngoboka 2018), which further problematizes the set of data in (2): as I show below, the locative phrase mu mujyi 'in the town' is an argument in both sentences.

Given that locatives are arguments in both applied and non-applied cases, the question arises as to what the contribution of the applicative is in cases like (2). I argue that the semantic distinction between variants can be captured by extending the analysis of applicatives in Jerro (2016b, 2020) in which applicativization marks an increase in lexical entailments associated with an internal argument, a view which builds on previous entailment-based work on argument realization (Ladusaw \& Dowty 1988, Dowty 1989, 1991, Ackerman \& Moore 2001, Beavers 2010). This approach allows a starting point for understanding the shifts in locative orientation observed in Kinyarwanda.

2. Locatives as arguments in Kinyarwanda. A typical feature of Bantu languages is the use of noun class prefixes which (roughly) categorize nouns based on their meaning (Katamba 2003). In Kinyarwanda, there are four locative prefixes: $a h a-, k u-, m u-$ and $i-$, which correspond to noun classes $16,17,18$, and 23 , respectively. ${ }^{2}$ Nouns that inherently describe a location are marked with class 16 , such as aha-ntu 'place' and ah-irengeye 'high place, place everyone can see'. 3

\footnotetext{
${ }^{1}$ Kinyarwanda has various morphophonological interactions, some of which are pertinent to the data presented here. First, vowel harmony determines the quality of the vowel of the applicative morpheme, which surfaces as /e/ or /i/. Second, the perfective suffix causes various consonant mutations at the end of the verbal stem, which often turns the applicative /-ir/ to /-ij/ (represented orthographically as "iy"), and in some cases it deletes the consonant of the applicative morpheme. Finally, past tense is the segment $a$ - before the verb stem; with vowel-initial stems, this segment is not represented in the orthography, but for clarity I will represent this information with $\emptyset$. There are various allomorphs of the perfective suffix $(-e,-y e,-e j e,-e y e)$, and the form corresponds to the consonant of the stem.

${ }^{2}$ The latter-most is sometimes labelled as class 19 (Overdulve 2002), class 25 (Grégoire 1975, Zeller \& Ngoboka 2018) and class 24 (Meeussen 1967). Maho (1999) and Katamba (2003) label this as class 23, which is the convention I adopt here.

${ }^{3}$ These definitions come from htp://kinyarwanda.net/.
} 
The other three locative prefixes ( $k u$ ' 17', $m u$ ' 18', and $i$ ' 23 ') appear in addition to the class prefix of the noun, and in Kinyarwanda orthography are separated from the noun.
a. kw' i-shuri
17 5-school
b. mw' ishyamba
18 5-forest
c. i Kigali
23 Kigali
'at the school'
'in the forest'
'at Kigali'

In Kinyarwanda, all locative classes (i.e. classes 16, 17, 18, and 23) trigger class 16 agreement morphology on the verb - a feature found across various "Great Lakes" Bantu languages (Maho 1999, Batibo 1985, Zeller \& Ngoboka 2018). There is considerable evidence from previous work that locative phrases are arguments in Kinyarwanda (Ngoboka 2016, Jerro 2016a, Zeller \& Ngoboka 2018), and I present four of the arguments for this here.

First, locative phrases can appear in argument positions, such as the subject of a passive (Bresnan \& Mchombo 1987, Bresnan \& Mchombo 1995:208-213, Zeller \& Ngoboka 2018:25-39). When in this position, the locative phrase triggers subject agreement with the main verb as in (4).
a. Mw' i-shyamba h-a-bon-w-e=mo
umw-ana.
18 5-forest 16S-PST-see-PASS-PRFV=18CL 1-child
'In the forest was found/seen a child.'
b. Mw' i-shyamba h-a-tem-e-w-e igi-ti n' umu-higi.
18 5-forest 16S-PST-cut-APPL-PASS-PRFV 7-tree by 1-hunter
'In the forest was cut the tree by the hunter.'

Crucially, the subject marker does not agree with the class 5 noun ishyamba 'forest', but rather the class 18 locative prefix $m u$ (shown by class 16 agreement on the verb).

Second, the locative can be object marked on the verbal stem (Bresnan \& Mchombo 1987:743-752, Bresnan \& Moshi 1990:150-152, Marten et al. 2007:6-12, though see Riedel \& Marten 2012 for critical discussion). In (5), a location that has been previously mentioned in the discourse, such as mи nzu 'in the house', may be replaced with the class 16 object marker $h a-$.
a. N-a-ha-bon-ye umw-ana.
1SGS-PST-16O-see-PRFV 1-child

'I saw the child there.'
b. Umu-higi y-a-ha-tem-ey-e igi-ti.
1-hunter 1S-PST-16O-cut-APPL-PRFV 7-tree
'The hunter cut the tree there.'

As with the data from passivization, object marking is permitted regardless of whether there is an applicative morpheme on the verb, suggesting locatives are arguments in both applied and non-applied variants of the verb.

Third, locative-marked phrases cannot productively appear with any verb. For example, with the verb ku-vuga 'to talk' in (6), a locative cannot be licensed unless there is an applicative:

(6) Habimana a-ri ku-vug-*(ir)-a mu n-zu.

Habimana 1S-be INF-talk-APPL-IMP 18 9-house

'Habimana is talking in the house.' 
In (6), the fact that the applicative licenses the locative mu nzu 'in the house' is evidence that for those verbs which do allow the locative without the applicative, the locative phrase is an argument selected (albeit optionally) by the verb.

Finally, the number of locatives permitted within a single clause is restricted in Kinyarwanda, as shown in (7); however, if locatives are adjuncts, it should be possible to stack locative phrases.

a. Nkusi a-ri kw-ambuka mu n-yanja

Nkusi 1S-be INF-cross 18 9-ocean

'Nkusi is crossing the ocean.'

b. *Nkusi a-ri kw-ambuka mu n-yanja i Mombasa.

Nkusi 1S-be INF-cross 18 9-ocean 23 Mombasa

Intended: 'Nkusi is crossing the ocean from Mombasa.'

c. Y- $\emptyset$-ambuk-*(iy)-e (mu) n-yanja i Mombasa.

1S-PST-cross-APPL-PRFV 18 9-ocean 23 Mombasa

'He crossed the ocean from Mombasa.'

The number of locative phrases is restricted, though this is not a semantic or pragmatic issue; an additional locative can be added via the applicative, as shown in $(7 \mathrm{c})$. This suggests that locative phrases are not adjuncts.

Further evidence for the fact that locatives are nominals is the fact that complements of the noun class prefix cannot be conjoined (Zeller \& Ngoboka 2018:17-18) and the fact that they have low tone (cp. the high tone of prepositional locatives in Tswana; Creissels 2011). Thus, from this section I conclude that locatives in Kinyarwanda are arguments.

3. The puzzle: Orientation and the applicative. The class of verbs of interest here are all transitive, non-motion verbs (see Jerro 2016a, 2020 for discussion of motion verbs with applicatives in Kinyarwanda) where there is a shift in orientation of the locative phrase between the applied and non-applied variants; the applied variant additionally states that all the participants are in the location described by the locative phrase. Consider, for example, the verb ku-mena 'to break' in (8), where the non-applied variant necessarily describes the location of the object; a sentence like (8a) is possible in a context where the child is standing outside the house and throws something through the window and breaks the cup (which is necessarily inside the house). In (8b), on the other hand, both the child and the cup must be inside the house.

a. Umw-ana y-a-menn-ye igi-kombe mu n-zu.

1-child 1S-PST-break-PRFV 7-cup 18 9-house

'The child broke the cup in the house.'

Speaker Judgment: Only the cup must be in the house

b. Umw-ana y-a-men-ey-e igi-kombe mu n-zu.

1-child 1S-PST-break-APPL-PRFV 7-cup 18 9-house

'The child broke the cup in the house.'

Speaker Judgment: The child and the cup must both be in the house

The same pattern is found with the perception verbs ku-bona 'to see' and ku-mva 'to hear': in the non-applied variant, only the object must be in the location described by the locative phrase, while in the applied variant, all participants must be in the location described by the locative 
phrase. For example, (9a) and (10a) could be used in a context where the subject is watching television and sees or hears (respectively) the child in the town depicted on the television; in the applied sentences in (b), on the other hand, the subject and the object are both in the location described by the locative phrase, i.e. both must be in town.

a. Umu-gabo y-a-bony-e umw-ana mu mu-jyi.

1-man 1S-PST-see-PRFV 1-child 18 3-town

'The man saw the child in the town.'

Speaker Judgment: Only the child must be in town

b. Umu-gabo y-a-bon-ey-e umw-ana mu mu-jyi.

1-man 1S-PST-see-APPL-PRFV 1-child 18 3-town

'The man saw the child in the town.'

Speaker Judgment: The man and the child are in town

a. Umu-gore y- $\emptyset$-umvis-e umw-ana mu n-zu.

1-woman 1S-PST-hear-PRFV 1-child 18 9-town

'The woman heard the child in the house.'

Speaker Judgment: Only the child must be the in house

b. Umu-gore y- $\emptyset$-umv-iy-e umw-ana mu n-zu.

1-woman 1S-PST-hear-APPL-PRFV 1-child 18 9-house

'The woman heard the child in the house.'

Speaker Judgment: The woman and the child are in the house

This difference in the description of the location of the various participants of the event has been referred to as "orientation" of locatives (Keenan \& Faltz 1985, Nam 1995, Kracht 2002). Previous work has shown that the orientation varies with different classes of verb and different types of preposition (Nam 1995:29-33), as well as principles relating to the nature of the participants and the events they are linked to (Kracht 2002).

For example, Nam (1995) makes several observations about the different locative orientation facts in English, such that verbs of placement are object-oriented, as in (11a), while verbs of judgment are subject-oriented, as in (11b).

a. Sarah installed the machine in the office

(object oriented)

b. John criticized Mary at the meeting

(subject oriented)

Kracht (2002: 221) proposes various principles about locative orientation, such as that "a non-directional locative is oriented towards the event." To the degree that this captures the English facts of static locatives (I leave this aside here), this will not provide insight into alternation in locative orientation meanings in Kinyarwanda, since in both applied and non-applied cases, such a generalization requires the locative is oriented towards the event. The question which arises from the Kinyarwanda data is distinct from the facts in English: what is the relationship between the locative in the applied and non-applied variants? The previous analyses of orientation shift in English are inapplicable given the presence of the applicative alternation and also the fact that locatives in Kinyarwanda are arguments. In the next section, I consider a possible analysis of the data in (2) and (8) - (10) based on previous approaches. I then present my proposal in $\S 5$. 
4. Possible analysis from previous work. One possible analysis of orientation shift in Kinyarwanda is that there is a difference in syntactic attachment between the two meanings: in the non-applied variant, the locative is an adnominal modifier of the verbal object, while in the applied variant, the locative is an argument of the verb and thus modifies all participants by virtue of modifying the event described by the verb. This view assumes that locative prefixes are variably prepositional or nominal, and the applied variant marks the licensing of an additional argument of the verb.

On this view, locative phrases in Kinyarwanda would have to be able to alternate between functioning as adnominal modifiers (in the case where they modify just the object) and verbal arguments (in the case where they modify the verb). In principle, this possibility would fit with the variation found in Bantu, where locatives in some languages are nominal and others are PPs (Welmers 1973, Bresnan \& Kanerva 1989, Bresnan 1994, Bresnan \& Mchombo 1995, Rugemalira 2004, Riedel \& Marten 2012, Guérois 2016, Zeller \& Ngoboka 2018). Thus, Kinyarwanda would be at an intermediary stage in the cline of (de)grammaticalization between the prepositional and nominal status of the locative phrase: specifically, in the non-applied variant, the locative phrase is a PP modifying the head noun; in the applied variant, the locative phrase is an applied object of the verb, schematized in (12).

a.

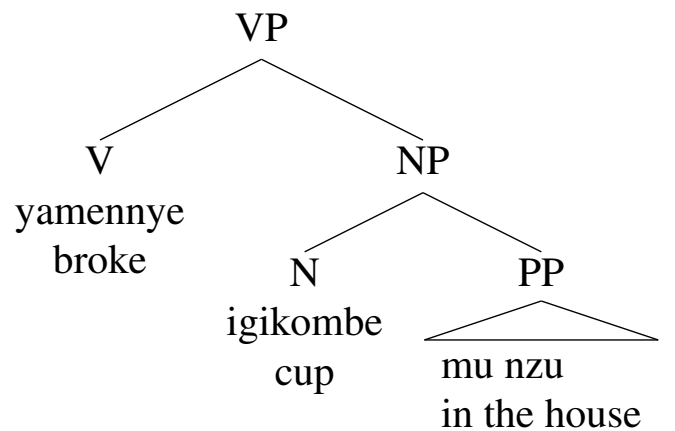

b.

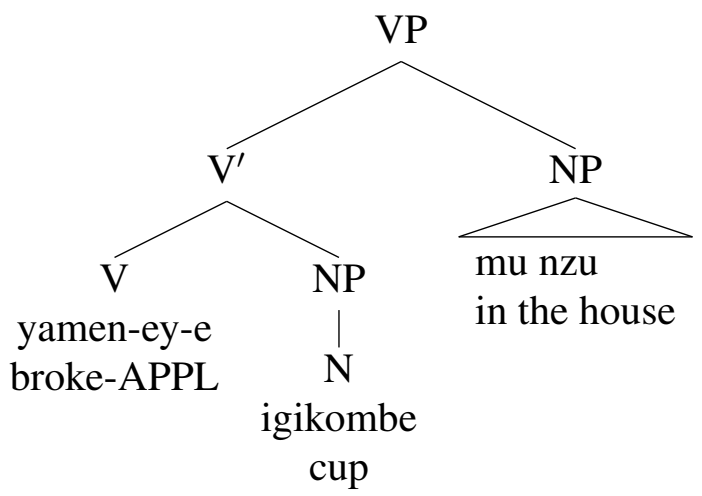

This is effectively the view proposed by Nam (1995: 48-49), ${ }^{4}$ who briefly analyzes locative applicatives in Kinyarwanda as 'predicate extensors', which turn $n$-place predicates into $n+1$

\footnotetext{
${ }^{4}$ See also Wunderlich (1991), who sketches a comparable account of applicatives in Chishona (Bantu; Zimbabwe). On his view, the function of the applicative is to add a new relation into the argument structure of the verb, and locatives in these languages are treated as relations between object and regions (instead of relations between two objects, as with English prepositions). The latter point is probably the right point of departure for illuminating the compositional behavior of locatives in Kinyarwanda (which I leave aside here), but it is not immediately clear how his approach would extend to the orientation facts described in $\S 3$.
} 
predicates, fitting with the more general view of applicatives as valence-increasing operations (see, e.g., Peterson 2007). ${ }^{5}$

Despite the conceptual attractiveness of this approach, there is evidence that the locatives in both the applied and non-applied variants of orientation-shifting verbs are verbal arguments, which means that the shift in meaning between alternants does not correspond to a syntactic difference in attachment. In particular, the difference in orientation persists even when the locative phrase is not in the position of an adnominal modifier. First, the (applied and non-applied) locative can be replaced with an object marker, and crucially, the meaning contrast in orientation is maintained, as shown in (13).

a. Umw-ana y-a-ha-menny-e igi-kombe.

1-child 1S-PST-16O-break-PRFV 7-cup

'The child broke the cup there.'

Speaker Judgment: The cup is at the location previously discussed in the discourse

b. Umw-ana y-a-ha-men-ey-e igi-kombe.

1-child 1S-PST-16O-break-APPL-PRFV 7-cup

'The child broke the cup there.'

Speaker Judgment: The child and the cup are at the location previously discussed in the discourse

Furthermore, the verbal object can be the subject of a passive to the exclusion of the locative phrase in both applied and non-applied cases, which suggests that the locative is crucially not an adnominal modifier in (14a). ${ }^{6}$

a. Igi-kombe cy-a-men-w-e mu mu-jyi n' umu-yobozi. 7-cup 7S-PST-break-PASS-PRFV 18 3-town by 1-chief

'The cup was broken in town by the chief.' (the cup is broken in the town; perhaps the chief sent someone to break it)

b. Igi-kombe cy-a-men-e-w-e mu mu-jyi n' umu-yobozi.

7-cup 7S-PST-break-APPL-PASS-PRFV 18 3-town by 1-chief

'The cup was broken in the town by the chief.' (the cup and the chief are in town)

From this evidence, I conclude that the locative phrase is an argument of the verb in both the applied and non-applied uses, and thus, contra the predicate extensor analysis, there is no additional argument in the applied variant since in both applied and non-applied variants the locative is an argument of the verb. In other words, there is no increase in valence between the two, which means that language-specific facts about Kinyarwanda preclude extending previous

\footnotetext{
${ }^{5} \mathrm{Nam}$ (1995) discusses the locative applicative -ho as described in Kimenyi (1980). The speakers I have consulted differ in their judgments of this form, and they instead treat it as a locative pronominal clitic parallel to $h a-$ in (5). See Jerro (2016a) for discussion of the meaning of -ho among such speakers.

${ }^{6}$ Neil Myler (p.c.) points out that the eventual analysis I outline below seems to predict that igikombe mu mujyi 'the cup in town' should not be permitted as the subject of a passive, since the locative cannot be an adnominal modifier. This is an empirical gap in my data, and thus it remains an open question as to whether this is possible. However, even if locatives could behave as adnominal modifiers, the question still remains as to how the orientation shift arises in cases where there is no adnominal modification in the absence of an overt locative phrase, such as (13), and I believe the account I give in $\S 5$ provides a starting point for the answer.
} 
analyses of locatives (let alone earlier accounts of orientation) to the data of locative orientation shifts in this language.

5. Capturing shifts in orientation in Kinyarwanda. On the view that locatives are arguments, I instead propose that applicatives in Kinyarwanda mark a paradigmatic relationship between applied and non-applied variants, and in the case of the relevant subclass of verbs from $\S 3$, there is an increase in the number of entailments associated with the internal locative argument. This view builds on entailment-based approaches to argument realization where the mapping to argument positions is mediated by specific grammatically-relevant entailments of participants (Ladusaw \& Dowty 1988, Dowty 1989, 1991, Ackerman \& Moore 2001, Beavers 2010).

5.1. ENTAILMENT-BASED APPROACHES TO ARGUMENT REALIZATION. A large body of work on the nature of verb meaning has proposed that the meaning of a verb is decomposed into event structures (Lakoff 1965, Jackendoff 1990, Dowty 1979, Hovav \& Levin 1988, Hale \& Keyser 1997, Levin \& Rappaport Hovav 1995, Wunderlich 1997, Rappaport Hovav \& Levin 1998, Davis \& Koenig 2000, Harley 2003, Koenig \& Davis 2006, Ramchand 2008, inter alia).

Entailment-based approaches to argument realization propose instead that a verb has a particular predicate argument structure, and each of the verb's arguments is associated with a set of entailments that must hold of that argument for the event to be appropriately described (see Levin \& Rappaport Hovav 2005: 51-68 for a summary).

Dowty defines those linguistically-significant thematic role types as L-thematic roles (1989: 77). With respect to argument realization, Dowty (1991) proposes that two roles are crucial for argument realization: Proto-Agent and Proto-Patient. On this view, the argument with the most Proto-Agent entailments is mapped to subject, and the argument with the most Proto-Patient entailments is mapped to object (see Dowty 1991: 572 for the relevant entailments).

Beavers (2010: 844-846) shows that with argument alternations (such as the spray/load alternation in English), Dowty's approach does not explain which Proto-Role entailments vary with a particular alternation. To resolve this, Beavers (2010) links the notion of a paradigmatic contrast between alternating variants with a hierarchy of minimally-contrasting L-thematic roles, via the MAP in (15).

\section{Morphosyntactic Alignment Principle (MAP)}

When participant $\mathrm{x}$ may be realized as either a direct or oblique argument of verb $\mathrm{V}$, it bears L-thematic role $R$ as a direct argument and L-thematic role $Q \subseteq_{M} R$ as an oblique.

(Beavers 2010: 848,(69))

The MAP captures the semantic differences of argument alternations, including the locative spray/load alternation and the conative alternation (Beavers 2010: 848-850), which are derived via independently-motivated scales of affectedness (which I leave aside here for sake of space).

With ditransitives, for example, Beavers shows that for subsets of ditransitive verbs which participate in the dative alternation (such as mail, send, and toss), the to variant encodes simple arrival of the theme at a goal, while the double object variant encodes arrival at the goal and receiving of the theme by the recipient.

a. Mukamana sent Uwase/\#Kigali a book.

b. Mukamana sent a book to Uwase/Kigali.

Thus the MAP predicts possible argument structure realizations available to an alternating verb, and it captures the fact that for any case for which some argument may be an object or oblique, 
the role associated with the realization as an object will have a stronger role (here, recipient) than the role associated with the realization as an oblique (here, goal).

In sum, the nature of a participant in two alternating positions is systematically governed by the semantic properties of the argument in a particular position, such as the observation (going back to Pesetsky 1995) that the meaning expressed by the direct object variant can be expressed by the to variant, but not vice versa (see also Krifka 2004, Rappaport Hovav \& Levin 2008).

5.2. APPLICATIVIZATION AS AN OUTPUT CONDITION. I adopt an entailment-based approach to capturing the applicative in Kinyarwanda, taking as central two interrelated observations from the literature on Bantu languages: first, the output of applicativization is more varied than often assumed, with evidence of varied outputs of applicativization which are determined in part by the meanings of particular verb classes (Rugemalira 1993, Cann \& Mabugu 2007, Jerro 2016b, Pacchiarotti 2017). Second, there is not always a valence-increasing function of applicatives (Trithart 1983, Harford 1993, Marten 2003, Poeta 2011, Jerro 2016b, Marten \& Mous 2016, Pacchiarotti 2017). To capture these facts, I analyze applicatives as marking a paradigmatic output condition, as defined in (17). ${ }^{7}$

(17) Applicativization Output Condition: In alternations between applied and non-applied variants of a verb, the applied variant has at least one internal argument, and the truth conditions associated with that internal argument are a strict superset of those associated with an internal argument of the non-applied variant.

(Jerro 2016b:57)

The AOC predicts three broad types of applicativization, on the assumption that an applicative in a given case can either add a semantic entailment, a new applied object slot, or both.

I assume two semantic denotations: one where the applicative links a thematic role $\phi$ to a wholesale new argument $y$, as in (18a), and one in which the thematic role associated with the applicative is linked to a participant $x_{1}$ of the verb, as in (19a) and (20a). ${ }^{8}$ In conjunction with these semantics, there may be a syntactic increase in valence, as in (18b) and (19b), or there may be no increase in valence, as in (20b).

(18) New Applied Object and New Thematic Role
a. $\lambda P \lambda y \lambda x_{1} \ldots \lambda x_{n} \lambda e\left[P\left(x_{1} \ldots x_{n}, e\right) \wedge \phi(e, y)\right]$
b. $\left\langle\mathrm{DP}_{a g} \ldots\right\rangle \Rightarrow\left\langle\mathrm{DP}_{a g} \mathrm{DP}_{\phi} \ldots\right\rangle$

(19) New Applied Object and Thematic Role from Verb

a. $\lambda P \lambda x_{1} \ldots \lambda x_{n} \lambda e\left[P\left(x_{1} \ldots x_{n}, e\right) \wedge \phi\left(e, x_{1}\right)\right]$

b. $\left\langle\underline{\mathrm{DP}_{a g}} \ldots\right\rangle \Rightarrow\left\langle\underline{\mathrm{DP}_{a g}} \mathrm{DP}_{\phi} \ldots\right\rangle$

(20) No Change in Valence and Increased Entailments of Existing IO
a. $\lambda P \lambda x_{1} \ldots \lambda x_{n} \lambda e\left[P\left(x_{1} \ldots x_{n}, e\right) \wedge \phi\left(e, x_{1}\right)\right]$
b. $\langle\ldots\rangle \Rightarrow\langle\ldots\rangle$

Jerro (2016b, 2020) shows that different verb classes in Kinyarwanda exemplify the three predicted types of outputs of the AOC in (18) - (20). While these are not the focus of the present

\footnotetext{
${ }^{7}$ See Jerro 2020 for a slightly different characterization of this condition, the details of which do not affect the present discussion.

${ }^{8}$ In these denotations, the notation of $x_{1} \ldots x_{n}$ indicates that all of the arguments of the predicate to which the applicative attaches are preserved as well as their respective ordering.
} 
discussion, I briefly outline the patterns here, though I refer the reader to earlier work for more detailed discussion.

First, the AOC predicts that there can be a new applied object and new thematic role associated with that argument as in (18), consistent with the "classic" view of applicatives. In Kinyarwanda, this is observed with the verbs gu-shaka 'want, search', gu-teka, 'to cook', ku-rya 'to eat', and ku-nywa 'to drink'. Take, for example, the verb ku-vuga 'to speak' where the applicative in (21b) licenses an additional (locative) argument to the argument structure of the non-applied variant in (21a).

a. Uwase a-ri ku-vug-a.

Uwase 1S-be INF-talk-IMP

'Uwase is talking.

b. Uwase a-ri ku-vug-ir-a mu n-zu.

Uwase 1S-be INF-talk-APPL-IMP 18 9-house

'Uwase is talking in the house.'

Second, the AOC allows a case where there is a new applied object, and the thematic role comes from the meaning of the verb — as in (19)—with motion verbs like kw-injira 'to enter', gu-sohoka 'exit', ku-manuka 'descend', ku-zamoka 'ascend', ku-rira 'to climb', $k w$-ambuka 'to cross', $k w$-ambuka 'to cross', gu-hagaruka 'to arise, alight', ku-guruka 'to fly', $k w$-iruka 'run', gu-tembera 'to go about', gu-simbuka 'to jump'. The different thematic role with the different verbs in (22) and (23) show that the thematic role of the applied object (a route or a source, respectively) comes from the verb itself and not the applicative.

a. N-di kw-injir-a mu n-zu.

1SGS-be INF-enter-IMP 18 9-house

'I am entering the house.'

b. N-di kw-injir-*(ir)-a mu mu-ryango (mu n-zu).

1SGS-be INF-enter-APPL-IMP 18 3-door 18 9-house

'I am entering the house through the door/\#to the door/\#from the door .'

$\begin{array}{ll}\text { a. Y- } \emptyset \text {-ambuts-e } & (\mathrm{mu}) \text { n-yanja. } \\ \text { 1S-PST-cross-PRFV } 18 \text { 9-ocean }\end{array}$

'He crossed the ocean.'

b. Y- $\emptyset$-ambuk-*(iy)-e (mu) n-yanja i Mombasa.

1S-PST-cross-APPL-PRFV 18 9-ocean 23 Mombasa

'He crossed the ocean from Mombasa/\#to Mombasa/\#through Mombasa.'

Finally, there are cases predicted by the AOC for which there is no change in the valence, and instead there is an increase in the lexical entailments associated with the non-Theme argument, corresponding to (20). This arises with the verbs gu-tera 'to throw at', gu-siga 'to leave something', ku-jyana 'to take', ku-zana 'to bring'. In (24a), the non-applied variant indicates that the rock is being thrown at Karekezi, while the applied variant in (24b) means that the rock is being thrown to Karekezi, with there being intended transfer of possession of the rock in the latter case. 
a. Habimana y-a-tey-e Karekezi i-buye .

Habimana 1S-PST-throw-PRFV Karekezi 5-rock

'Habimana threw the rock at Karekezi.'

b. Habimana y-a-ter-ey-e Karekezi i-buye.

Habimana 1S-PST-throw-APPL-PRFV Karekezi 5-rock

'Habimana threw the rock to Karekezi.'

To summarize, the AOC is a meta-constraint that restricts the space of possible applied verb meanings, and the crucial insight is that the marking of the applicative corresponds to a semantic increase in entailments associated with internal arguments.

5.3. ORIENTATION SHIFT IN KINYARWANDA. My proposal is that the shift in locative orientation in Kinyarwanda described in $\S 3$ can be captured by appealing to the AOC. Following Maienborn (2001) and others, I assume that a locative is a relation loc between a located entity (here, $y$ ) and a landmark (here, $l$ ), stating that $\mathrm{y}$ is located in the spatial region of the landmark. ${ }^{9} \mathrm{I}$ assume that these are linked a neo-Davidsonian event variable $e$. A sentence like that in (25) would have the meaning in (26).

$$
\text { Umu-gabo y-a-bony-e umw-ana mu mu-jyi. }
$$

1-man 1S-PST-see-PRFV 1-child 18 3-town

'The man saw the child in the town.'

Speaker Judgment: Only the child must be in town

$$
\exists e\left[\operatorname{seeing}^{\prime}(e) \wedge \operatorname{agent}^{\prime}\left(\operatorname{man}^{\prime}, e\right) \wedge \operatorname{theme}^{\prime}\left(\operatorname{child}^{\prime}, e\right) \wedge \operatorname{loc}^{\prime}\left(\text { town }^{\prime}, \operatorname{child}^{\prime}, e\right)\right]
$$

I argue that locative orientation shift in Kinyarwanda is an instance in which an additional entailment is present in the applied variant, but with no corresponding increase in valence (cp. the ditransitive verbs in (24)). I argue that the orientation shifting verbs have a locative argument that describes the location of the object in the event, effectively treating them as a specific class of ditransitive verbs. I assume that a feature of verbs in this class is that the locative can be existentially bound, which captures the transitive use of these verbs where there is no overt locative phrase (but still entails that the object is in a location, which is necessarily true), as in (28) where the locative entity is existentially bound.

$$
\begin{array}{ll}
\text { Umu-gabo y-a-bony-e umw-ana. } & \text { um 1-man } \\
\text { 1S-PST-see-PRFV } & 1-c h i l d
\end{array}
$$

'The man saw the child.'

$$
\exists l \exists e\left[\operatorname{seeing}^{\prime}(e) \wedge \operatorname{agent}^{\prime}\left(\operatorname{man}^{\prime}, e\right) \wedge \operatorname{theme}^{\prime}\left(\operatorname{child}^{\prime}, e\right) \wedge l o c^{\prime}\left(l, \operatorname{child}^{\prime}, e\right)\right]
$$

I argue that the function of the applicative for the verbs in $\S 3$ is that it associates the location described by the verb's locative argument with all participants in the event. I implement this by a polysemous sense of the locative applicative morpheme which describes the location of all participants of the event, lexicalized with this class of transitive, non-motion verbs.

\footnotetext{
${ }^{9}$ For reasons of space, I leave aside the composition of the locative phrase with verbs which subcategorize for locations; see Wunderlich (1991: 607-612) for discussion of how to combine locative-selecting verbs with the appropriate locative complements. I set aside the nuances of meaning conveyed by different locative prefixes, which may encode various static and directional meanings, depending on the meaning of the verb as well as pragmatic context.
} 
$\llbracket i r_{\text {shift }} \rrbracket:=\lambda P \lambda y \lambda l \lambda x \lambda e\left[P(x, y, l, e) \wedge l o c^{\prime}(l, y, e) \wedge \forall z[z\right.$ is a participant in $e \rightarrow z$ is at the location denoted by $l]]$

On this view, the semantics of the locative argument are associated with two entailments regarding the location of the event, the one being a superset of the other.

$$
\begin{aligned}
& \llbracket k u b o n a \rrbracket:=\lambda y \lambda l \lambda x \lambda e\left[\operatorname{seeing}^{\prime}(e) \wedge \operatorname{agent}^{\prime}(x, e) \wedge \operatorname{theme}^{\prime}(y, e) \wedge \operatorname{loc}^{\prime}(l, y, e)\right] \\
& \llbracket k u b o n e r a \rrbracket:=\lambda y \lambda l \lambda x \lambda e\left[\operatorname{seeing}^{\prime}(e) \wedge \operatorname{agent}^{\prime}(x, e) \wedge \operatorname{theme}^{\prime}(y, e) \wedge \operatorname{loc}^{\prime}(l, y, e) \wedge \forall z[z \text { is }\right. \\
& \text { a participant in } e \rightarrow z \text { is at the location denoted by } l]]
\end{aligned}
$$

Thus, the locative argument is associated with more lexical entailments in the applied variant, consistent with the AOC.

Evidence for locating all participants in the region described by $l$ is that with lexical ditransitives like $g u$ - $h a$ 'to give', all three participants must be in the location denoted by the locative phrase.

a. Karemera y-a-hay-e Nkusi in-zu i Kigali.

Karemera 1S-PST-give-PRFV Nkusi 9-house 23 Kigali

'Karemera gave Nkusi the house in Kigali.'

Speaker Judgment: Karemera and Nkusi are elsewhere; the house is in Kigali

b. Karemera y-a-her-ey-e Nkusi in-zu i Kigali.

Karemera 1S-PST-give-appl-prfv Nkusi 9-house 23 Kigali

'Karemera gave Nkusi the house in Kigali.'

Speaker Judgment: Karemera, Nkusi, and the house are in Kigali

The data in (32) show that all participants are entailed to be in the location described by the locative phrase $i$ Kigali 'at/in Kigali', which is consistent with the applicative semantics proposed in (29) that all participants are in the location described by the locative phrase.

It is worth noting that, within the space of the AOC, other kinds of addition could also be marked by the applicative, such as a new beneficiary applied object. In such a case, the prediction is that the locative orientation should be the same as in the non-applied variant, since the AOC is satisfied via the licensing of the beneficiary applied object. This is borne out in (33), where the locative only necessarily describes the location of the house.

Karemera y- $\emptyset$-ubak-iy-e Nkusi in-zu mu mu-jyi.

Karemera 1S-PST-build-APPL-PRFV Nkusi 9-house 18 3-town

'Karemera built the house for Nkusi in the town.'

Speaker Judgment: Only the house is entailed to be in the town

The AOC, then, captures various ways in which new entailments (and sometimes new participants) are introduced into the truth conditional content of internal arguments of a particular verb.

6. Conclusion. In this paper I have presented a new set of data in which the orientation of the locative differs in the applied and non-applied variants of certain verbs. Because locative phrases are always arguments in Kinyarwanda, the difference cannot be due to the variable attachment of the locative as an argument or adjunct. I argue that this contrast can be captured by appealing to the Applicativization Output Condition, in which an applied variant of a verb is required to have 
a stricter set of lexical entailments associated with an internal argument than the non-applied variant. This study not only further expands the understanding of locatives in Bantu languages, which vary greatly in the status of locative phrases, but it also provides further motivation for an entailment-based approach to applicativization.

\section{References}

Ackerman, Farrell \& John Moore. 2001. Proto-properties and grammatical encoding: A correspondence theory of argument selection. Stanford: CSLI Publications.

Batibo, Herman. 1985. Le kesukuma (langue bantu de Tanzania): phonologie, morphologie. Paris: Centre de Recherches, d'Échanges et de Documentation Universitaire, Kenya.

Beavers, John. 2010. The structure of lexical meaning: Why semantics really matters. Language 86. 821-864. https://doi.org/10.1353/lan.2010.0040.

Bresnan, Joan. 1994. Locative inversion and the architecture of universal grammar. Language 70(1). 72-131. https://doi.org/10.2307/416741.

Bresnan, Joan \& Jonni Kanerva. 1989. Locative inversion in Chicheŵa: A case study of factorization in grammar. Linguistic Inquiry 20(1). 1-50. https://www.jstor.org/stable/4178612.

Bresnan, Joan \& Sam A. Mchombo. 1987. Topic, pronoun, and agreement in Chichewa. Language 63(4). 741-782. https://doi.org/10.2307/415717.

Bresnan, Joan \& Sam A. Mchombo. 1995. The lexical integrity principle: Evidence from Bantu. Natural Language \& Linguistic Theory 13(2). 181-254. https://doi.org/10.1007/BF00992782.

Bresnan, Joan \& Lioba Moshi. 1990. Object asymmetries in comparative Bantu syntax. Linguistic Inquiry 21(2). 147-185. https://www.jstor.org/stable/4178668.

Cann, Ronnie \& Patricia Mabugu. 2007. Constructional polysemy: The applicative construction in chiShona. In Marina Rakova, Gergely Petho \& Csilla Rakosi (eds.), The cognitive basis of polysemy (Metalinguistica Vol. 19). 221-245. New York: Peter Lang.

Creissels, Denis. 2011. Tswana locatives and their status in the inversion construction. Africana Linguistica 17. 33-52.

Davis, Anthony \& Jean-Pierre Koenig. 2000. Linking as constraints on word classes in a hierarchical lexicon. Language 76(1). 56-91. https://doi.org/10.2307/417393.

Dowty, David. 1979. Word meaning and Montague grammar. Dordrecht: Kluwer. Dowty, David. 1989. On the semantic content of the notion 'thematic role'. In Gennaro Chierchia, Barbara H. Partee \& Raymond Turner (eds.), Properties, types, and meaning. 69-130. Dordrecht: Kluwer.

Dowty, David. 1991. Thematic proto-roles and argument selection. Language 67(3). 547-619. https://doi.org/10.2307/415037.

Grégoire, Claire. 1975. Les locatifs en bantou. Tervuren: Musée royal de l'Afrique Centrale.

Guérois, Rozenn. 2016. The locative system in Cuwabo and Makhuwa (P30 Bantu languages). Linguistique et langues africaines 2. 43-75.

Hale, Kenneth \& Samuel Keyser. 1997. The limits of argument structure. In Amaya Mendikoetxea \& Myriam Uribe-Etxebarria (eds.), Theoretical issues at the morphology-syntax interface. 203-230. Bilbao: Universida de País Vasco, Euskal Herriko Univertsitatca.

Harford, C. 1993. The applicative in ChiShona and Lexical Mapping Theory. In Sam A. Mchombo (ed.), Theoretical aspects of Bantu grammar. 93-111. Stanford: CSLI Publications.

Harley, Heidi. 2003. Possession in the double object construction. In Pierre Pica \& Johan Rooryck (eds.), Linguistic variation yearbook 2. 31-70. Amsterdam: John Benjamins.

Hovav, Malka Rappaport \& Beth Levin. 1988. What to do with $\theta$-roles. In Wendy Wilkins (ed.), Syntax and semantics vol. 21. 7-36. New York: Academic Press.

Jackendoff, Ray. 1983. Semantics and cognition. Cambridge, MA: MIT Press. 
Jackendoff, Ray. 1990. Semantic structures. Cambridge, MA: MIT Press.

Jerro, Kyle. 2016a. Locative applicatives and the semantics of verb class. In Doris Payne, Sara Pacchiarotti \& Mokaya Bosire (eds.), The selected proceedings of the 46th Annual Conference on African Linguistics. 289-309. Berlin: Language Science Press.

Jerro, Kyle. 2016b. The syntax and semantics of applicative morphology in Bantu. Austin: University of Texas at Austin dissertation.

Jerro, Kyle. 2020. The semantics of applicatives in Kinyarwanda. Unpublished ms., University of Essex.

Katamba, Francis. 2003. Bantu nominal morphology. In Derek Nurse \& Gérard Philippson (eds.), The Bantu languages. 103-120. New York: Routledge.

Keenan, Edward \& Leonard Faltz. 1985. Boolean semantics for natural language. Dordrecht: D. Reidel.

Kimenyi, Alexandre. 1980. A relational grammar of Kinyarwanda. Berkeley: University of California Press.

Koenig, Jean-Pierre \& Anthony Davis. 2006. The KEY to lexical semantic representations. Journal of Linguistics 42(1). 71-108. https://doi.org/10.1017/S0022226705003695.

Kracht, Marcus. 2002. On the semantics of locatives. Linguistics and Philosophy 25. 157-232.

Krifka, Manfred. 2004. Semantic and pragmatic conditions for the dative alternation. Korean Journal of English Language and Linguistics 4. 1-32.

Ladusaw, William \& David Dowty. 1988. Toward a non-grammatical account of thematic roles. In Wendy Wilkins (ed.), Thematic relations. 62-72. San Diego: Academic Press.

Lakoff, George. 1965. On the nature of syntactic irregularity. Bloomington: Indiana University dissertation.

Levin, Beth \& Malka Rappaport Hovav. 1995. Unaccusativity: At the syntax-lexical semantics interface. Cambridge, MA: MIT Press.

Levin, Beth \& Malka Rappaport Hovav. 2005. Argument realization. Cambridge: Cambridge University Press.

Maho, Jouni Filip. 1999. A comparative study of Bantu noun classes. Göteborg: Acta Universitatis Gothoburgensis.

Maienborn, Claudia. 2001. On the position and interpretation of locative modifiers. Natural Language Semantics 9(2). 191-240. https://doi.org/10.1023/A:1012405607146.

Marten, Lutz. 2003. The dynamics of Bantu applied verbs: An analysis at the syntax-pragmatics interface. In Kézié K. Lébikaza (ed.), Acts du 3e congrès mondial de linguistique africainelomé 2000. 207-221. Köln: Köppe.

Marten, Lutz. 2010. The great siSwati locative shift. In Anne Breitbarth, Christopher Lucas, Sheila Watts \& David Willis (eds.), Continuity and change in grammar. 249-267. Amsterdam: John Benjamins.

Marten, Lutz, Nancy Kula \& Nhlanhla Thwala. 2007. Parameters of morphosyntactic variation in Bantu. Transactions of the Philological Society 105. 253-338. https://doi.org/10.1111/j.1467968X.2007.00190.x.

Marten, Lutz \& Maarten Mous. 2016. Non-valency-changing valency-changing derivations. In Rose-Juliet Anyanwu (ed.), Transitivity in african languages: Frankfurter afrikanistische blätter. Cologne: Rüdiger Köppe Verlag.

Mchombo, Sam. 2004. The syntax of Chichêwa. Cambridge: Cambridge University Press.

Meeussen, Achille Emiel. 1967. Bantu grammatical reconstructions. Africana Linguistica 3. 79121.

Nam, Seungho. 1995. Semantics of locative prepositional phrases in English. Los Angeles: Univesity of California dissertation. 
Ngoboka, Jean Paul. 2016. Locatives in Kinyarwanda. Durban: University of KwaZulu-Natal dissertation.

Overdulve, Cornelis-Marinus. 2002. Précis de grammaire kinyarwanda. Kabgayi, Rwanda: Imprimerie de Kabgayi.

Pacchiarotti, Sara. 2017. Bantu applicative construction types involving *-id: Form, functions and diachrony. Eugene: The University of Oregon dissertation.

Pesetsky, David. 1995. Zero syntax: Experiences and cascades. Cambridge, MA: MIT Press.

Peterson, David. 2007. Applicative constructions. Oxford: Oxford University Press.

Poeta, Teresa. 2011. What's an applicative? the meaning and function of Swahili applicatives: A study beyond the well-researched constructions. London: School of Oriental and African Studies (SOAS) MA thesis.

Ramchand, Gillian. 2008. Verb meaning and the lexicon: A first phase syntax. Cambridge: Cambridge University Press.

Rappaport Hovav, Malka \& Beth Levin. 1998. Building verb meanings. In Miriam Butt \& Wilhelm Geuder (eds.), The projection of arguments: Lexical and compositional factors. 97134. Stanford: CSLI Publications.

Rappaport Hovav, Malka \& Beth Levin. 2008. The English dative alternation: A case for verb sensitivity. Journal of Linguistics 44. 129-167.https://doi.org/10.1017/S0022226707004975.

Riedel, Kristina \& Lutz Marten. 2012. Locative object marking and the argument-adjunct distinction. Southern African Linguistics and Applied Language Studies 30. 277-292.

Rugemalira, Josephat Muhozi. 1993. Runyambo verb extensions and constraints on predicate structure. Berkeley: University of California dissertation.

Rugemalira, Josephat Muhozi. 2004. Locative arguments in Bantu. In Proceedings of the 4th World Congress of African Linguistics. 285-296. Cologne: Rüdiger Köppe Verlag.

Trithart, Mary Lee. 1983. The applied affix and transitivity: A historical study of Bantu. Los Angeles: University of California dissertation.

Welmers, William Everrett. 1973. African language structures. Berkeley: University of Califonia Press.

Wunderlich, Dieter. 1991. How do prepositional phrases fit into compositional syntax and semantics? Linguistics 29(4). 591-622. https://doi.org/10.1515/ling.1991.29.4.591.

Wunderlich, Dieter. 1997. Cause and the structure of verbs. Linguistic Inquiry 28. 27-68. https://www.jstor.org/stable/4178964.

Zeller, Jochen \& Jean Paul Ngoboka. 2018. Agreement with locatives in Kinyarwanda: a comparative analysis. Journal of African Languages and Linguistics 39(1). 65-106.

Zwarts, Joost. 2005. Prepositional aspect and the algebra of paths. Linguistics and Philosophy 28. 739-779. https://doi.org/10.1007/s10988-005-2466-y.

Zwarts, Joost \& Yoad Winters. 1997. A semantic characterization of locative PPs. In Aaron Lawson (ed.), Proceedings of Semantics and Linguistic Theory (SALT) 7. 294-311. Ithaca: Cornell University. https://doi.org/10.3765/salt.v7i0.2798.

Zwarts, Joost \& Yoad Winters. 2000. Vector space semantics: A model-theoretic analysis of locative prepositions. Journal of Logic, Language and Information 9(2). 169-211. https://doi.org/10.1023/A:1008384416604. 